\title{
Pengaruh Teknologi dan Inovasi dalam Persaingan Traditional Food di Kalimantan Tengah
}

\author{
Danes Jaya Negara ${ }^{1}$, Vivy Kristinae ${ }^{2}$ \\ Universitas Palangka Raya
}

Korespondensi: vivykristinae84@gmail.com

\begin{abstract}
Abstrak
Usaha Kecil Menengah (UKM) di Indonesia memiliki potensi yang dapat dikembangkan dalam berbagai sektor dan strategi. Kalimantan Tengah memiliki UKM yang bergerak pada sektor bidang makanan tradisional memiliki persaingan dalam menarik konsumen karena banyaknya makanan dari luar negeri yang mengancam keberadaan pelaku usaha makanan tradisional. Tujuan dari penelitian menganalisis sejauh mana Teknologi dan Inovasi dapat berjalan sebagai proses dalam informasi dan komunikasi kepada pelanggan sebagai keunggulan bersaing dalam sektor makanan saat ini. Penelitian menggunakan metode kuantitatif dengan alat analisis regresi linear berganda, melibatkan 50 responden pengusaha makanan dan minimal tradisional agar mampu bertahan dalam persaingan (Competitive advantage)
\end{abstract}

Kata Kunci : UKM, Traditional Food, Teknologi, Inovasi, Competitive Advantage

\section{Abstract}

Small and Medium Enterprises (SMEs) in Indonesia have the potential to be developed in various sectors and strategies. Central Kalimantan has SMEs that are engaged in the traditional food sector having competition in attracting consumers because of the many foods from abroad that threaten the existence of traditional food businesses. The purpose of the study analyzes the extent to which Technology and Innovation can run as a process in information and communication to customers as a competitive advantage in the food sector today. The research uses quantitative methods with multiple linear regression analysis tools, involving 50 respondents of traditional food and minimal entrepreneurs to be able to survive in competition (Competitive advantage)

Keywords: SMEs, Traditional Food, Technology, Innovation, Competitive Advantage

\section{A. Pendahuluan}

Indonesia adalah negara yang memiliki Usaha Kecil dan Menengah (UKM) di dukung oleh berbagai pihak seperti pemerintah, bank swasta ataupun pengusaha bidang Industri Kecil Menengah. Kalimantan Tengah memiliki 13 kabupaten dan 1 kota Palangka Raya, dari sumber data Dinas kopersai dan UKM Provinsi. Kalimantan Tengah tentang keberadaan UKM Tradisional Food pada 3 (tiga) tahun terakhir maret 2019, ada penurunan pendapatan rata-rata sekitar $30 \%$ per-tahun dan yang menjadi poin penting penelitian ini berdasarkan pengamatan langsung, banyaknya makanan luar (korea,jepang,junk food) yang dapat mengancam keberadaan UKM sektor makanan tradisional di tambah dengan harga yang kompetitif. Menurut Adhikari and Gill (2011) bisnis dalam sektor besar dan kecil adalah suatu usaha yang dalam pemasaran untuk dapat bertahan dengan teori Competitive Advantage untuk selalu mengelola sumber daya pelaku bisnis dengan didukung kemampuan pemasaran dan teknologi, yang berfokus pada konsumen dan pesaing.

Sebelum memasuki pemasaran di lingkungan pasar secara global, pelaku usaha harus dapat mengidentifikasi pesaing untuk mengatasi konflik dan tantangan yang terus berubah. Selain itu, bisnis tersebut harus mengembangkan produk dengan inovasi berdasarkan tujuan inovasi dalam strategi pemasaran dan berhasilnya penerapan teknik tergantung pada integrasi pelaku usaha dalam kemampuan pemasaran (Alegre, Sengupta, \& Lapiedra, 2011). Dalam sebuah studi tentang interaksi antara Research \& Development dan program pemasaran menemukan bahwa inovasi produk di industri tergantung teknologi sebagai faktor penting dalam tahap pengembangan produk (Hsu, 2011). Memasuki era digitalisasi 
UKM mendapat dukungan pemerintah dengan memberikan pelatihan untuk dapat memasarkan produk dengan keahlian yang di dorong kemampuan menggunakan teknologi sebagai proses inovasi pemasaran produk makanan tradisional sangat penting untuk terapkan sebagai media jualan secara daring. Pemasaran online menurut (Gupta, Malhotra, Czinkota, \& Foroudi, 2016) strategi pemasaran dirancang untuk memandu suatu perusahaan untuk menggunakannya sumber daya untuk memenuhi persyaratan pelanggan sasaran dan mewujudkan tujuan pemasaran lebih efisien daripada para pesaingnya, serta mempertimbangkan strategi pemasaran untuk melibatkan empat dimensi, termasuk strategi branding, strategi biaya, strategi saluran, dan strategi inovasi. Dari perspektif ini, strategi pemasaran dan inovasi produk terkait erat. Menurut Zineldin and Philipson (2007) mendefinisikan strategi pemasaran sebagai seperangkat prinsip bisnis yang digunakan perusahaan untuk melayani pelanggan dan mencapai profitabilitas mengenai jenis pemasarannya dan strategi melalui aspek dimasukkan 4P (Produk, Harga, Tempat, dan Promosi) menggunakan ide pemasaran sebagai variabel pengukuran untuk survei kuesioner dan analisis strategi pemasaran produk.

Strategis berbasis pada kasus-kasus produk yang sukses,terdiri dari faktor-faktor strategis yang praktis terhadap inovasi desain dari serangkaian proses untuk mencapai tujuan inovasi spesifik desain produk, dan keunggulan kompetitif dalam desain yang berbeda dan menarik (desain yang inovatif) di dukung teknologi menunjukkan metode pencapaian tujuan desain inovasi (Bauer \& Auer-Srnka, 2012). Tim desain dapat mengimplementasikan, merancang strategi dengan menganalisis kebutuhan pelanggan dan dampaknya terhadap pesaing dalam mencapai tujuan kinerja perusahaan (Hsu, 2006). Pelaku usaha UKM sering menghabiskan banyak waktu dan sumber daya yang sangat besar mengembangkan teknologi dan produk baru sebagai informasi untuk mengeksploitasi teknologi dan produk baru yang telah dikembangkannya. Menurut Yong-Ki, Sally, Namho, Kwanghoon, and Jong-Won (2016)menyatakan bisnis yang lebih menyadari skala ekonomi dan ruang lingkup dengan mengeksploitasi pengetahuan di berbagai pasar dengan sumber daya (terutama teknologi) dan eksploitasi pasar bagian di berbagai pasar cenderung spesifik untuk profitabilitas dan produk juga akan slit di tiru, karena telah beredar di media online atau cetak.

Beberapa produk makanan tradisional yang di buat oleh UKM di Kalimantan Tengah adalah keripik singkah, kerupuk amplang, ikan saluang goreng, ikan lais goreng dan lainnya. Harga bervariasi mulai dari Rp.10.000,00 - Rp. 150.000,00 yang diolah dengan di awasi Badan Pengawas Obat dan Makanan (BPOM) dan berlabel halal dari Majelis Ulama Indonesia (MUI), dapat di jadikan cenderamata maupun konsumsi masyarakat. Sebagian besar penelitian sebelumnya mengusulkan bahwa perangkat teknologi informasi (TI) memengaruhi langkah-langkah efisiensi dan tidak banyak memiliki dampak yang signifikan dalam kegagalan mencapai pasar, karena penggunaan TI pada langkah-langkah efektivitas (Mutiarni, R, 2016) seperti informasi kualitas produk, inovasi pemasaran produk, dan kinerja pasar secara langsung signifikan dapat memengaruhi kinerja produk di pasar melalui kemampuan teknologi sebagai proses inovasi (Ahn \& Seo, 2018)

Tradisional food UKM di Kalimantan Tengah memiliki keterbatasan inovasi dalam keunggulan bersaingnya berkaitan dalam pemasaran dan promosi dengan teknologi sebagai media untuk pemasaran dan pengenalan produk kepada konsumen. Manfaat teknologi terhadap inovasi dalam proses dan produk dapat menjadi strategi bisnis untuk mendapatkan konsumen dari dalam dan menjangkau konsumen dari luar kota dengan pemasaran produk (informasi dan komunikasi) melalui teknologi seperti sosial media dengan audio visual atau website pelaku usaha, di sisi waktu ini lebih efisien dan efektif dalam inovasi. 
Berdasarkan latar belakang yang telah disampaikan dengan didukung beberapa literatur pendukung maka rumusan masalah dalam penelitian ini adalah :1) menganalisis teknologi sebagai strategi bersaing dalam pemasaran untuk memberikan informasi tentang produk makanan tradisional UKM dan 2) menganalisis inovasi sebagai proses pemasaran dengan audio visual, sehingga dapat menarik konsumen dan meningkatkan desain produk misalnya rasa dan kemasan untuk menarik konsumen.

\section{B. KAJIAN PUSTAKA}

\section{Keunggulan Bersaing}

Keunggulan bersaing merupakan teori mengacu pada keunggulan posisi (lebih dari pesaing) yang berasal dari eksploitasi kemampuan, termasuk keuntungan berbiaya rendah (biaya lebih rendah daripada pesaing)dan keunggulan diferensiasi (produk yang berbeda) dan menjadi acuan kinerja inovasi produk mengacu pada nilai ekonomi menjadi pendorong kompetitif (Adeniran \& Johnston, 2012). Menurut teori keunggulan kompetitif, keunggulan kompetitif posisional termasuk keunggulan biaya rendah dan keunggulan diferensiasi adalah faktor penentu utama kinerja. Teori kompetitif keuntungan juga menyatakan bahwa sangat penting untuk menggunakan kapabilitas / kompetensi perusahaan sejauh mungkin mendapatkan keunggulan kompetitif posisional kinerja yang unggul, perusahaan harus terlebih dahulu mengembangkan kemampuan pemasaran. Pemasaran dalam melakukan inovasi harus memungkinkan perusahaan untuk memberikan informasi produk / layanan ini lebih baik daripada pesaing, sehingga melalui pencapaian keunggulan kompetitif posisional, itulah kemampuan pemasaran dapat mewujudkan potensi kinerjasecara tepat jika keunggulan kompetitif dapat dipertimbangkan secara bersamaan dalam program strategi bersaing dengan indikator : (1) kami telah memperoleh keunggulan strategis dibandingkan pesaing kami, (2) produk baru kami ditawarkan dengan pertimbangan tanggung jawab sosial,(3) produk kami menggabungkan pengetahuan dan konsep ketahanan lingkungan (Robert M Grant, 1991).

\section{Teori Resources Based View (RBV) dan Teknologi}

Teori tampilan berbasis sumber daya dari perusahaan untuk menjelaskan dan menganalisis efek inovasi, penciptaan teknologi, manajemen kualitas, dan kemampuan manajemen informasi pada kinerja organisasi dalam keunggulan bersaing. Dari perspektif saling melengkapi sumber daya, manajemen informasi dan kemampuan mencakup rutinitas atau praktik yang melengkapi inovasi, penciptaan teknologi, dan manajemen mutu. Teori RBV berpendapat bahwa sumber daya menghasilkan keunggulan kompetitif dapat menjangkau batas-batas organisasi dan menjadi hubungan antar organisasi. Kemampuan manajemen informasi adalah kapasitas yang dilakukan oleh UKM yang memiliki keahlian wirausaha dan penting menerapkan teknologi informasi untuk mengendalikan implementasi suatu informasi sebagai strategi penciptaan teknologi (Dustin, Bharat, \& Jitendra, 2014). Inovasi dan kinerja organisasi semakin meningkat dapat menjadi penentu utama keunggulan kompetitif perusahaan karena inovasi memainkan peran penting ketika pelanggan membangun hubungan dengan perusahaan dan relatif stabil dan sadar bahwa kecenderungan hubungan yang diciptakan oleh pelanggan dengan pelaku usaha kategori produk tertentu (Deniz, 2016). Teknologi adalah proses penting berdasarkan pada pengetahuan gabungan antara sumber daya dan inovasi sebagai komponen kunci dari pengetahuan manajemen sebagai ukuran indikator : (1) mampu meningkatkan kemampuan usaha seiring waktu, (2) pelaku usaha memiliki pengetahuan pembuatan teknologi khusus beberapa aspek dari usaha, (3) Pelaku usaha percaya bahwa kemampuan kreasi dari teknologi, (4) pelaku usaha 
percaya diri mengandalkan teknologi informasi sehingga lebih efektif dan efisien (Adeniran \& Johnston, 2012).

Menurut Calantone, Chan, and Cui (2006) pentingnya penerapan teknologi : 1. Teknologi berubah sangat cepat seiring adanya produk baru, proses dan layanan baru dari pesaing, dan ini mendorong usaha entrepreneurial untuk bersaing dan sukses. Yang harus dilakukan adalah menyesuaikan diri dengan inovasi teknologi baru. 2. Efek perubahan lingkungan terhadap siklus hidup produk semakin pendek, yang artinya bahwa produk atau layanan lama harus digantikan dengan yang baru dalam waktu cepat, dan ini bisa terjadi karena ada pemikiran kreatif untuk melakukan inovasi. 3. Konsumen saat ini ahli dalam memilih produk dan untuk menuntut pemenuhan kebutuhan. Harapan kebaruan dalam inovasi dengan teknologi untuk pemenuhan kebutuhan kualitas, pembaruan, dan harga. Oleh karena itu skill inovatif dibutuhkan untuk memuaskan kebutuhan konsumen sekaligus mempertahankan konsumen sebagai pelanggan.4, Perubahan pasar dan teknologi yang berubah sangat cepat, ide yang bagus dapat semakin mudah ditiru, membutuhkan informasi metode penggunaan produk, proses yang baru dan lebih baik, dan layanan yang lebih cepat secara kontinyu.

\section{Inovasi}

Inovasi adalah proses untuk menciptakan, memperoleh, berbagi, dan memanfaatkan pengetahuan untuk mengembangkan kinerja dan pembelajaran organisasi, modifikasi, pemanfaatan,serta mengakses pengetahuan. Inovasi dan kemampuan kinerja organisasi mempengaruhi usaha untuk lebih cenderung melakukan sumber daya manajerial dalam hal waktu dan upaya untuk hubungan antar perusahaan (Aboulnasr, Narasimhan, Blair, \& Chandy, 2008). Penelitian mencakup inovasi sebagai variabel memiliki indikator : (1) Pelaku usaha berbagi informasi dalam pengetahuan tentang inovasi dalam sektor, (2) Pelaku usaha berbagi pengalaman atau pengetahuan inovasi, (3) pelaku usaha menerapkan pengetahuan inovasi yang dipelajari pengalaman, (4) pelaku usaha menggunakan pengetahuan inovasi untuk menyelesaikan masalah baru, (5) pelaku usaha menerapkan pengetahuan inovasi untuk menyelesaikan persaingan dalam sektor (Y. Chen, Wang, Nevo, Benitez-Amado, \& Kou, 2015).

Inovasi pemasaran sering kali menyediakan perbaikan cepat yang inovatif melalui solusi yang menekankan modifikasi, ekstensi, dan produk yang berisiko rendah dalam perubahan desain.inovasi pemasaran dapat menyajikan strategi menarik (keterjangkauan) untuk mencoba membalikkan metode penjualan yang menurun untuk meningkatkan pendapatan dengan logika inovasi pemasaran menekankan pertumbuhan penjualan dengan kurva permintaan konsumen dari kebutuhan ke segmen pasar melalui pengiriman nilai yang lebih baik kepada pelanggan (Bygballe \& Ingemansson, 2014).

\section{Teknologi dalam Inovasi}

Meningkatnya tekanan daya saing global, mengurangi usia siklus produk dan kemudahan meniru mengharuskan perusahaan untuk berinovasi agar tetap dapat bertahan dalam bisnis yang kompetitif. Dengan kata lain, inovasi telah menjadi platform untuk produktivitas, peningkatan, pertumbuhan volume penjualan, dan daya saing perusahaan. Kondisi demikian juga mendesak perusahaan untuk menjadi inovatif dalam rangka meningkatkan daya saing produk mereka dalam hal desain,kualitas, dan keandalan layanan. Karena itu, perusahaan harus meningkatkan kemampuan inovasi mereka mengembangkan dan mengkomersialkan teknologi baru secara efektif dan membawa perkembangan inovasi dengan teknologi untuk memperkuat keunggulan kompetitif mereka (Albort-Morant, LealMillán, \& Cepeda-Carrión, 2016). Mengkonseptualisasikan Teknologi dalam inovasi, mendefinisikan TI sebagai jenis sumber daya khusus yang perlu secara efektif 
meningkatkan produk yang ada,proses pembuatan dan untuk membuat yang baru. Dalam hal ini, TI termasuk produk untuk kemampuan inovasi yang mengacu pada serangkaian langkah yang saling terkait yang digunakan untuk terlibat dalam inovasi produk yang berbeda, seperti pengembangan produk baru dan produk yang sudah (Berghman, Matthyssens, \& Vandenbempt, 2012). Proses kemampuan inovasi mengacu pada teknologi yang digunakan dalam mengembangkan inovasi

dan memungkinkan pelaku usaha untuk memilih dan memanfaatkan teknologi secara strategis untuk mengembangkan teknik baru, proses, dan metode produksi. Berdasarkan pada pengetahuan dan keahlian bahwa kemampuan proses inovasi berasal dari pembelajaran proses dimana perusahaan dapat menginternalisasi pengetahuan baru untuk menghasilkan teknologi mengubah suatu metode dan akhirnya mendapatkan proses baru yang lebih baik (Aljanabi, 2018).

\section{Kerangka Penelitian}

Berdasarkan kajian pustaka yang telah disampaikan dengan didukung penelitian terdahulu serta fenomena yang terjadi saat ini maka kerangka penelitian dan hipotesis yang diangkat adalah:

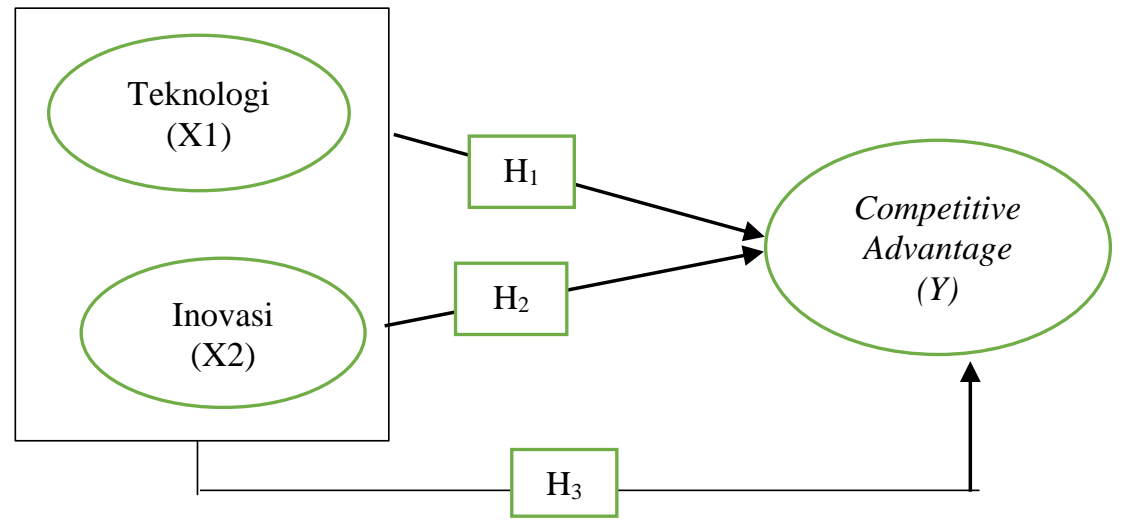

Gambar 1. kerangka penelitian

$\mathrm{H}_{1}$ : Teknologi berpengaruh untuk meningkatkan Competitive Advantage

$\mathrm{H}_{2}$ : Inovasi berpengaruh untuk meningkatkan Competitive Advantage

$\mathrm{H}_{3}$ : Teknologi dan Inovasi secara bersama-sama berpengaruh untuk meningkatkan Competitive Advantage

\section{Metode Penelitian}

Penelitian ini berjenis kuantitatif, yang dilakukan untuk menjawab pertanyaan penelitian melalui model persamaan struktural yang diusulkan untuk menjelaskan pengaruh Teknologi $\left(\mathrm{X}_{1}\right)$ dan Inovasi $\left(\mathrm{X}_{2}\right)$ terhadap Competitive Advantage (Y). Populasi dalam penelitian ini adalah pelaku UKM di Kalimantan Tengah yang tidak diketahui jumlahnya, sehingga pengambilan sampel yang diambil menggunakan metode non probabilitas sampling. Dari perhitungan selanjutnya diambil sampel sebanyak 50 responden dengan kriteria telah menjalankan usaha minimal selama 3 (tiga) tahun. Data yang digunakan adalah data primer yang bersumber langsung dari responden berupa jawaban atas sejumlah pertanyaan yang diajukan peneliti dengan beberapa pilihan jawaban menggunakan skala Likert, mulai opsi sangat setuju (bernilai 7) hingga sangat tidak setuju (bernilai 5).

Alat Analisa menggunakan Regresi Linear Berganda, Uji - T dan Uji F dengan alat bantu pengolahan data menggunakan SPSS 22.0 


\section{Hasil Penelitian dan pembahasan}

Dari hasil analisis data primer dengan menggunakan regresi untuk variabel yang diajukan tampak hasilnya sebagai berikut:

Tabel 1. Uji determinasi-Model Summary ${ }^{b}$

\begin{tabular}{|c|c|c|c|c|}
\hline Model & $\mathrm{R}$ & R Square & Adjusted R Square & Std. Error of the Estimate \\
\hline 1 & $.915^{\mathrm{a}}$ & .863 & .841 &, 729 \\
\hline
\end{tabular}

Berdasarkan hasil Tabel 1, koefisien determinasi pengaruh dari variabel terikat (X) terhadap variabel bebas (Y) adalah sebesar 0,841 . Hal ini menunjukkan bahwa sebesar $84,1 \%$ variable bebas dipengaruhi oleh variable terikat, dan sisanya sebesar $15,9 \%$ di pengaruhi oleh faktor lain yang tidak diteliti.

Untuk menguji hipotesis yang diajukan, dilakukan Uji-T dan Uji-F, dan hasilnya tampak pada tabel berikut:

Tabel 2. Uji -T

Coefficients $^{\mathrm{a}}$

\begin{tabular}{|c|c|c|c|c|c|c|}
\hline & \multirow[b]{2}{*}{ Model } & \multicolumn{2}{|c|}{ Unstandardized Coefficients } & \multicolumn{3}{|l|}{$\begin{array}{l}\text { Standardized } \\
\text { Coefficients }\end{array}$} \\
\hline & & $\mathrm{B}$ & Std. Error & Beta & $\mathrm{t}$ & Sig. \\
\hline \multirow[t]{3}{*}{1} & (Constant) & 3.646 & .748 & & 2.109 & .005 \\
\hline & X1 (Teknologi) & .575 & .071 & .565 & 6.445 & .000 \\
\hline & X2 (Inovasi) & .468 & .062 & .451 & 5.823 & .001 \\
\hline
\end{tabular}

a. Dependent Variable: y

Sumber: Data Primer diolah, 2018

Tabel 3.Uji - F ANOVA $^{\mathrm{b}}$

\begin{tabular}{lllllll}
\hline Model & & Sum of & & & \\
& & Squares & df & Mean Square & F & Sig. \\
\hline 1 & Regression & 12.892 & 2 & 26.146 & 41.499 & $.000^{\mathrm{a}}$ \\
\hline & Residual & 106.075 & 47 &, 549 & & \\
\hline & Total & 118.967 & 49 & & & \\
\hline
\end{tabular}

a. Predictors: (Constant), Teknologi, Inovasi, Teknologi Inovasi. b. Dependent Variable: y (Competitive Advantage) Sumber: Data Primer diolah, 2018

Dari tabel diatas menunjukkan bahwa seluruh hipotesis diterima. Hal ini tampak dari nilai sig $0,00<0,05$. Hasil penelitian ini mendukung penelitian yang dilakukan Agostini (Agostini \& Nosella, 2016) yang menyatakan bahwa agar bisnis UKM unggul, peran teknologi sebagai pendukung setiap bisnis UKM terutama dalam pemasaran sangat dibutuhkan. Demikian juga inovasi, mutlak diperlukan agar UKM menjadi unggul dan mampu bersaing. Hal ini sesuai dengan penelitian yang dilakukan oleh Alegree (Alegre et al., 2011). Inovasi dan teknologi mutlak diperlukan oleh pelaku UKM untuk : 1) Berbagi informasi tentang inovasi 2) Berbagi pengalaman tentang inovasi, 3) Menerapkan inovasi yang dipelajari berdasarkan pengalaman, 4) Menggunakan teknologi dan inovasi untuk menyelesaikan masalah baru, 5) Menerapkan teknologi dan inovasi untuk menyelesaikan persaingan. Pengetahuan pelaku usaha terhadap kebaikan dan keuntungan menggunakan teknologi sangat mendukung keberhasilan bisnis (A. S.-Y. Chen \& Hou, 2016; Y. Chen et al., 2015). Kemampuan pelaku usaha menerapkan teknologi juga mendukung proses pemasaran atau program pemasaran (Ahn \& Seo, 2018). Inovasi juga diperlukan guna mencapai competitive 
advantage karena ide-ide yang inovatif ditambah dengan penerapan teknologi akan semakin menguatkan pelaku UKM untuk bersaing di pasaran (Gupta et al., 2016; Hsu, 2011; Adeniran \& Johnston, 2012; Adhikari \& Gill, 2011; AH Affendy, 2015)

\section{E. Penutup}

Dari hasil penelitian dan pembahasan yang telah disampaikan tampak bahwa teknologi dan inovasi terbukti secara positif dan signifikan berpengaruh terhadap competitive adavantage. Karena itu disarankan kepada pihak-pihak yang terkait, khususnya bagi pemerintah Kalimantan Tengah untuk memberikan pelatihan sebagai pengembangan kemampan dan keahlian pelaku usaha terlebih mengenai aplikasi teknologi sehingga beberapa UKM yang belum mampu dapat mampu bertahan di persaingan bisnis saat ini.

\section{Daftar Pustaka}

Aboulnasr, K., Narasimhan, O., Blair, E., \& Chandy, R. (2008). Competitive Response to Radical Product Innovations. Journal of Marketing, 72, 17.

Adeniran, T. V., \& Johnston, K. A. (2012). Investigating the dynamic capabilities and competitive advantage of South African SMEs. African Journal of Business Management, 6(11), 4088-4099. doi: http://dx.doi.org/10.5897/AJBM11.1673

Adhikari, A., \& Gill, M. S. (2011). Impact of resources, capabilities and technology on market orientation of Indian B2B firms. Journal of Services Research, 11(2), 74.

Agostini, L., \& Nosella, A. (2016). The central role of a company's technological reputation in enhancing customer performance in the B2B context of SMEs. Journal of Engineering and Technology Management, 42, 1-14. doi: 10.1016/j.jengtecman.2016.08.001

AH Affendy, T., Nizam,MS Farid. (2015). Entrepreneurial Orientation Effects on Market Orientation and SMEs Business Performance - A SEM Approach. Society of Interdisciplinary Business Research (www.sibresearch.org), 4(3), 259-271.

Ahn, J. A., \& Seo, S. (2018). Consumer responses to interactive restaurant self-service technology (IRSST): The role of gadget-loving propensity. International Journal of Hospitality Management, 74, 109-121. doi: 10.1016/j.ijhm.2018.02.020

Albort-Morant, G., Leal-Millán, A., \& Cepeda-Carrión, G. (2016). The antecedents of green innovation performance: A model of learning and capabilities. Journal of Business Research, 69(11), 4912-4917. doi: 10.1016/j.jbusres.2016.04.052

Alegre, J., Sengupta, K., \& Lapiedra, R. (2011). Knowledge management and innovation performance in a high-tech SMEs industry. International Small Business Journal, 31(4), 454-470. doi: 10.1177/0266242611417472

Aljanabi, A. R. A. (2018). The mediating role of absorptive capacity on the relationship between entrepreneurial orientation and technological innovation capabilities. International Journal of Entrepreneurial Behavior \& Research, 24(4), 818-841. doi: 10.1108/ijebr-07-2017-0233

Bauer, M., \& Auer-Srnka, K. J. (2012). The life cycle concept in marketing research. Journal of Historical Research in Marketing, 4(1), 68-96. doi: http://dx.doi.org/10.1108/17557501211195073

Berghman, L., Matthyssens, P., \& Vandenbempt, K. (2012). Value innovation, deliberate learning mechanisms and information from supply chain partners. Industrial Marketing Management, 41(1), 27-39. doi: 10.1016/j.indmarman.2011.11.014 
Bygballe, L. E., \& Ingemansson, M. (2014). The logic of innovation in construction. Industrial Marketing Management, 43(3), 512-524. doi: 10.1016/j.indmarman.2013.12.019

Calantone, R. J., Chan, K., \& Cui, A. S. (2006). Decomposing product innovativeness and its effects on new product success. Journal of Product Innovation Management, 23(5), 408-421.

Chen, A. S.-Y., \& Hou, Y.-H. (2016). The effects of ethical leadership, voice behavior and climates for innovation on creativity: A moderated mediation examination. The Leadership Quarterly, 27(1), 1-13. doi: 10.1016/j.leaqua.2015.10.007

Chen, Y., Wang, Y., Nevo, S., Benitez-Amado, J., \& Kou, G. (2015). IT capabilities and product innovation performance: The roles of corporate entrepreneurship and competitive intensity. Information \& Management, 52(6), 643-657. doi: 10.1016/j.im.2015.05.003

Deniz, K. (2016). Strategic entrepreneurship: mediating the entrepreneurial orientationperformance link. Management Decision, 54(1), 24-43. doi: 10.1108/MD-11-20140660

Dustin, G., Bharat, M., \& Jitendra, M. (2014). Competitive Advantage and Motivating Innovation. Advances In Management, 7(1), 8.

Grant, R. M. (1991). The resource-based theory of competitive advantage: implications for strategy formulation. California Management Review, 33(3), 114-135.

Grant, R. M. (1991). The Resource-Based Theory of Competitive Advantage: Implications for Strategy Formulation. California Management Review, 3, 114-134.

Gupta, S., Malhotra, N. K., Czinkota, M., \& Foroudi, P. (2016). Marketing innovation: A consequence of competitiveness. Journal of Business Research, 69(12), 5671-5681. doi: 10.1016/j.jbusres.2016.02.042

Hsu, Y. (2011). Design innovation and marketing strategy in successful product competition. The Journal of Business \& Industrial Marketing, 26(4), 223-236. doi: http://dx.doi.org/10.1108/08858621111126974

Mutiarni, R. (2016). EFEKTIVITAS PEMBELAJARAN MICROSOSFT EXCEL BERBASIS INTERAKTIF PADA MATA KULIAH TEKNOLOGI INFORMASI DAN KOMUNIKASI (TIK)(Study Kasus Pada Mahasiswa Manajemen STIE PGRI Dewantara Jombang). Eksis: Jurnal Riset Ekonomi dan Bisnis, 11(2)

Tabachnick, B. G., \& Fidell, L. S. (2012). Using Multivariate Statistics (6 ed.). New York: Pearson Publisher.

Yong-Ki, L., Sally, Y. K., Namho, C., Kwanghoon, A., \& Jong-Won, L. (2016). When social media met commerce: a model of perceived customer value in group-buying. Journal of Services Marketing, 30(4), 398-410. doi: 10.1108/JSM-04-2014-0129

Zineldin, M., \& Philipson, S. (2007). Kotler And Borden Are Not Dead: Myth of Relationship Marketing And Truth of The 4Ps. Journal of Consumer Marketing, 24(4), 229-241. doi: 10.1108/07363760710756011 